related arthritis. Uveitis and ANA were only observed in 4 (11.4\%) children with oligoarthritis: 3 with persistent oligoarthritis $(11.5 \%, 27,3 \%$ of the ANA positive patients) and 1 with extended oligoarthritis $(11,1 \%, 25 \%$ of the ANA positive patients). No case of severe uveitis was detected. Erosions were present in $4(5.5 \%)$ children: $2(33.3 \%)$ with polyarthritis, 1 $(38.4 \%)$ with persistent oligoarthritis and 1 (11.1\%) with extended oligoarthritis. $17(23.6 \%)$ patients were treated with methotrexate (MTX): 5 (55.5\%) with extended oligoarthritis; 3 (11.5\%) with persistent oligoarthritis; 6 (37.5\%) with systemic arthritis; $2(33.3 \%)$ with polyarthritis and 1 (50\%) with psoriatic arthritis. 106 intraarticular (i.a.) injections of steroids were administered in 36 (50\%) children: knee in 25 (69.6\%) cases, ankle in $9(25 \%)$ cases, elbow in $4(11.1 \%)$ cases and hand small joints in $4(11.1 \%)$ cases. The i.a. injections were administered in 16 patients with persistent oligoarthritis, 8 with extended oligoarthritis, 5 with systemic JIA and 7 in the other subtypes.

Conclusion The pattern of joint involvement is similar to previous published results. Although, uveitis was less clearly associated with the presence of antinuclear antibodies and also appeared to be milder in comparison to other series. I.a. injections were the mainstay of therapy in the persistent oligoarthritis subtype, but MTX had to be used in 55,5\% of the extended oligoarthritis group, stressing the importance of differentiating this 2 patterns of involvement.

\section{OP0088 CHILDHOOD SARCOIDOSIS: EXPERIENCE IN A PAEDIATRIC RHEUMATOLOGY CENTRE}

A Gedalia, AK Shetty, LR Espinoza. Pediatrics and Medicine, LSU Health Sciences Center/ Children's Hospital, New Orleans, USA

\subsection{6/annrheumdis-2001.493}

Background Sarcoidosis is a multisystemic granulomatous disease of unknown aetiology, most commonly affecting young and middle-aged adults. It is relatively uncommon in children.

Objectives To report our experience on the diagnosis, management and outcome of childhood sarcoidosis in a Paediatric Rheumatology settings.

Methods A retrospective chart review to detect patients with sarcoidosis seen by the Rheumatology Service from 1993 to 1998. All patients had initial evaluation that included a complete history and physical examination and an eye evaluation by an Ophthalmologist. Laboratory evaluation at initial and follow-up visits included CBC, ESR, renal and liver function tests, urinalysis, serum calcium, serum immunoglobulins, and Angiotensin converting enzyme (ACE) and chest radiograph. Clinical response to therapy was measured by clinical severity score that we devised. These data were analysed at diagnosis and follow-up visits.

Results Sixteen patients with sarcoidosis were identified. Thirteen were African-Americans. There were nine females and seven males with mean age at onset of 8 (range, 1-15) years; mean age at diagnosis of 10 (range, 2-16) years. Four patients had onset before age 4 years and were classified as early-onset sarcoidosis. Common manifestations included uveitis (69\%), pulmonary disease (44\%), hilar adenopathy (44\%), arthritis (31\%), generalised lymphadenopathy $(25 \%)$, and skin rash $(25 \%)$. Unusual associated features included abdominal aortic aneurysm (1 case), nephrocalcinosis (1), membranous nephropathy (1), and marrow disease (3). The diagnosis was confirmed by demonstration of noncaseating granuloma on a biopsy specimen associated with negative stains for mycobacteria and fungi in 12 patients. The tissue biopsy sites included peripheral lymph node (1), skin (1), kidney (1), lung (3), conjunctival nodule (1), lacrimal gland (1), bone (2), bone marrow (1), and tonsil (1). Laboratory abnormalities included elevated ACE serum levels (82\%), hyper IgG $(82 \%)$, anaemia $(75 \%)$, elevated ESR $(70 \%)$, and hypercalcemia (12\%). Treatment with oral prednisone $(1-2 \mathrm{mg} / \mathrm{kg} /$ day $)$ was initiated in all 15 symptomatic patients with significant improvement. Prednisone was tapered and successfully discontinued within a mean duration of one year in four patients. Low-dose methotrexate (MTX) in oral dose of $10-15 \mathrm{mg} / \mathrm{m}^{2} /$ week was administered in 11 patients. On oral MTX therapy steroid dose was successfully tapered and discontinued within a mean duration of 2.6 years in 6 patients, and was tapered from $1.2 \mathrm{mg} / \mathrm{kg}$ / day to $0.2 \mathrm{mg} / \mathrm{kg} /$ day within 3.5 years in four. One patient received cytoxan. Two patients relapsed 6 months after discontinuation of MTX. No deaths were noted. Morbidity included persistent iritis (3 patients), restrictive lung disease (1) and joint sequelae (1).

Conclusion Childhood sarcoidosis is prevalent in the State of Louisiana. This enigmatic disorder may involve a broad spectrum of body systems and may present in unusual ways in children. Low-dose MTX seems to be effective, steroid-sparing, and safe adjunct to treat sarcoidosis with multisystem involvement. Longterm follow-up is critical for better understanding of the guide of therapy and prognosis in this disease.

\section{OP0090 SOLUBLE ADHESION MOLECULES ICAM-1 AND E- SELECTIN IN JUVENILE ARTHRITIS - CLINICAL AND LABORATORY CORRELATIONS}

P Dolezalova, P Telekesova, D Nemcova, J Hoza. Department of Pediatrics and Adolescent Medicine, Charles University in Prague, 1st Medical Faculty, Prague 2, Czech Republic

\subsection{6/annrheumdis-2001.494}

Background Raised concentrations of soluble intercellular adhesion molecule-1 (ICAM-1) and E-selectin (E-sel) are believed to reflect processes of their up-regulation and endothelial cell (EC) activation by various inflammatory stimuli. Resulting enhancement of cell infiltration is a pre-recquisite of tissue damage.

Objectives To evaluate serum and synovial fluid (SF) concentrations of ICAM-1 and E-sel in patients with juvenile idiopathic arthritis (JIA) and in paediatric controls and to correlate them with clinical and laboratory variables.

Methods Total of 33 JIA patients (mean age 10 y) were evaluated: 18 with polyarthritis (JIApoly) disease course (mean active joint count 9) and 15 with oligoarthritis (JIAoligo). Paediatric age-matched control groups consisted of 11 Henoch-Schönlein purpura (HSP) and 10 febrile (FC) patients and 28 healthy children. Current medication, ESR, CRP and FBC were recorded. Soluble ICAM-1 and E-sel in serum and SF were measured by commercially available sandwich ELISA kits.

Results Significant negative correlation with age was observed for the whole group (ICAM-1: p $<0.01$, E-sel: p $<0.001$ ), Esel correlated with leucocyte and thrombocyte counts $(\mathrm{p}<$ $0.01)$, both molecules with CRP $(\mathrm{p}<0.05)$ and with each other $(\mathrm{p}<0.01)$. For JIA group as a whole no correlation was found with disease duration or therapy used. JIAoligo did not differ from controls, in JIApoly levels of both molecules were higher than in healthy ( $\mathrm{p}<0.001$ for ICAM-1, $\mathrm{p}<0.06$ for E-sel), but not febrile controls. Both molecules correlated with active joint count ( $\mathrm{p}<0.01)$. In 13 JIA patients (9 oligo, 4 polyarthritis) no correlation was found of SF ICAM-1 and E-sel concentrations 
with SF leucocyte counts. Although levels of ICAM-1 appeared to be higher in SF than in serum the difference was not significant.

Conclusion High concentrations of soluble ICAM-1 and E-sel in JIA patients with polyarthritis are reported here for the first time. Bloom ${ }^{1}$ and de Benedetti ${ }^{2}$ found increased ICAM- 1 and Esel levels only in systemic JIA. In our patients only 3 had systemic onset disease, none showed signs of vasculitis or infection. Our finding of correlation of both molecule levels with joint count supports the hypothesis of synovial EC origin of these molecules. It brings interesting insight in suspected disease pathogenesis in terms of endothelial activation, leucocyte migration and angiogenesis. ICAM-1 and E-sel could be a marker of aggressive disease, but their predictive value needs to be further studied.

\section{REFERENCES}

1 Bloom BJ, Miller LC, Tucker LB, et al. Soluble adhesion molecules in juvenile rheumatoid arthritis. J Rheumatol. 1999;26:2044-8

2 De Benedetti F, Vivarelli M, Pignatti $P$, et al. Circulating levels of soluble E-selectin, P-selectin and intercellular adhesion molecule-1 in patients with juvenile idiopathic arthritis. J Rheumatol. 2000;27:2246-50

\section{OP0092 EFFECTS OF CALCITONIN AND CALCIUM TREATMENT ON BONE MINERAL DENSITY IN PATIENTS WITH JUVENILE CHRONIC ARTHRITIS}

${ }^{1} \mathrm{R}$ Celiker, ${ }^{1} \mathrm{~S}$ Bal, ${ }^{2} \mathrm{~A}$ Bakkaloglu, ${ }^{3} \mathrm{E}$ Ozaydin, ${ }^{3} \mathrm{~T}$ Coskun. ${ }^{1}$ Department of Physical Medicine and Rehabilitation; ${ }^{2}$ Pediatric Nephrology; ${ }^{3}$ Metabolism and Nutrition, Hacettepe University, School of Medicine, Ankara, Turkey

10.1136/annrheumdis-2001.495

Background Osteoporosis is one of the most important and common complications in children with Juvenile Chronic Arthritis (JCA). Osteoporosis in JCA has a multifactorial origin. Reduced or absent physical activity, decreased production of endogenous vitamin D, anaemia and drug treatment, especially steroid treatment are thought to be possible mechanisms of osteoporosis in children with JCA.

Objectives The aim of this study was to evaluate the effect of calcitonin and calcium treatment on bone mineral status in patients with JCA.

Methods According to EULAR criteria 16 patients $(7$ male, 9 female) with JCA (2 patients with systemic, 2 patients with oligoarticular and 12 patients with polyarticular type) and 13 age and sex similar healthy controls ( 8 male, 5 female) were included in the study. The mean age of the patients and control groups were $10,12 \pm 3,80$ and 10,2 $\pm 3,26$ years respectively. Patients with JCA were randomly treated for 6 months with either $50 \mathrm{IU} /$ day salmon calcitonin administered intranasal and $500 \mathrm{mg}$ calcium per day per oral (Group 1) or $500 \mathrm{mg} /$ day calcium only (Group 2) to determine their effect on bone status. Bone mineral density (BMD) of the lumbar spine at the L1-L4 level was measured by dual energy x-ray absorptiometry (Hologic QDR-4500 A). Disease activity was determined by clinical and laboratory evaluation (serum erythrocyte sedimentation rate and $\mathrm{C}$ reactive protein levels), and Juvenile Arthritis Functional Assessment Report (JAFAR). Data from BMD measurements were obtained at baseline and 6 months later.

Results The mean age and the duration of disease for groups $1 \& 2$ were 9,4 \pm 4,31 years and 41,10 \pm 42,29 months and $11,33 \pm 2,65$ years and 40,66 $\pm 33,31$ months respectively. The mean baseline BMD results were $0.458 \pm 0.157 \mathrm{gr} / \mathrm{cm}^{2}$ in Group $1,0.580 \pm 0.137 \mathrm{gr} / \mathrm{cm}^{2}$ in Group 2 and $0.599 \pm 0.096$ $\mathrm{gr} / \mathrm{cm}^{2}$ in control group. BMD values of the JCA group were significantly lower than the control group $(\mathrm{p}=0,038)$. In both treatment groups (Group 1 and Group 2) there were an increase in $\mathrm{BMD}$ values $(\mathrm{p} 1=0,05$ and $\mathrm{p} 2=0,028$ respectively). As the increments were compared the difference in between was not statistically significant $(\mathrm{p}>0.05)$.

Conclusion Our results suggest that children with JCA would benefit from calcium supplementation and calcitonin treatment. No adverse effects were observed in both treatment groups during the follow-up period.

\section{OP0094 STEADY-STATE PLASMA CONCENTRATIONS OF ROFECOXIB IN CHILDREN WITH JUVENILE RHEUMATOID ARTHRITIS}

${ }^{1} \mathrm{KE}$ Truitt, ${ }^{2} \mathrm{M}$ Ferrandiz, ${ }^{3} \mathrm{M}$ Kiss, ${ }^{4} \mathrm{OT}$ Forre, ${ }^{1} \mathrm{AG}$ Porras, ${ }^{1} \mathrm{P}$ Wong, E St. Rose ${ }^{1}$ LM DeTora'. 'Pulmonary-Immunology, Merck Research Laboratories, Rahway, USA; ${ }^{2}$ Instituto Nacional de Salud Del Nino, Vieja La Molina; ${ }^{3}$ Oslo Sanitetsforenings Revmatismesykehus, Oslo, Peru; ${ }^{4}$ Rheumatology, Clinics Hospital of the School of Medicine of the University of Sao Paulo, Sao Paulo, Brazil, Norway

10.1136/annrheumdis-2001.496

\section{Background}

Objectives To compare the steady-state AUC $(0-24$ h) of rofecoxib, dosed@ approx $0.32 \mathrm{mg} / \mathrm{kg} /$ day in children aged 2 to 17 years vs. adult historical controls who received one 25 -mg tablet daily (mean weight of $77.7 \mathrm{~kg}$, corresponding to $\sim 0.32 \mathrm{mg} / \mathrm{kg}$ / day).

Methods Two trials were performed. In one, adolescent JRA patients (12 to 17 years) received $12.5 \mathrm{mg}$ or $25 \mathrm{mg}$ tablets to approximate $0.32 \mathrm{mg} / \mathrm{kg} /$ day. In another, JRA patients aged 2-11 years received rofecoxib $2.5 \mathrm{mg} / \mathrm{ml}$ suspension to approx. 0.32 $\mathrm{mg} / \mathrm{kg} /$ day. Both formulations have equivalent bioavailability. All patients received once-daily rofecoxib for at least 8 days (to presumptive steady state) then trough and post-dose blood samples were obtained for up to $24 \mathrm{~h}$. To minimise the number of blood samples for 2-5 year-olds, 2 sampling schedules with different time points were used. Comparison to adult historical controls was made by calculating $\operatorname{AUC}(0-24 \mathrm{hr})$ geometric mean ratio (GMR) with corresponding 90\% confidence intervals (CI) for specific paediatric age groups: $12-17 \mathrm{yrs} ; 6-11 \mathrm{yrs}$; and $2-5 \mathrm{yrs}$; relative to adult controls. Similar comparisons were made for Cmax. Summary statistics for AUC(0-24 hr) were calculated for each treatment (12.5 mg or $25 \mathrm{mg}$ Rofecoxib) in patients $12-17$ years.

Results See Table 1. 12-17 yr-old patients taking $12.5 \mathrm{mg}$ or 25 mg rofecoxib showed similar exposure to adult controls receiving the same dose. Rofecoxib was generally well-tolerated in all patients and age ranges studied.

\begin{tabular}{|c|c|c|c|c|c|}
\hline & Paediatric & Groups & $\begin{array}{l}\text { Versus } \\
\text { Adult }\end{array}$ & Historical & Controls \\
\hline & $\begin{array}{l}\text { AUC (0-24 } \\
h r)\end{array}$ & $\mathrm{ng} \cdot \mathrm{hr} / \mathrm{mL}$ & & Cmax & $\mathrm{ng} / \mathrm{mL}$ \\
\hline & Geometric & GMR $(90 \%$ & & Geometric & GMR $(90 \%$ \\
\hline & Mean & $\mathrm{Cl})$ & & Mean & $\mathrm{Cl})$ \\
\hline $\begin{array}{l}2-5 \text { year- } \\
\text { olds }\end{array}$ & 2581 & $\begin{array}{l}0.57(0.48 \\
0.73)\end{array}$ & & 204 & $\begin{array}{l}0.58(0.45 \\
0.74)\end{array}$ \\
\hline $\begin{array}{l}\text { 6-11 year- } \\
\text { olds }\end{array}$ & 2885 & $\begin{array}{l}0.64(0.54 \\
0.74)\end{array}$ & & 208 & $\begin{array}{l}0.57(0.48 \\
0.67)\end{array}$ \\
\hline
\end{tabular}

